\title{
Discogen-DNA Complex Films at Air-Water and Air-Solid Interfaces
}

\author{
Alpana Nayak and K. A. Suresh* \\ Raman Research Institute, Sadashivanagar, Bangalore - 560 080, India.
}

Supporting Information

${ }^{*}$ Corresponding author. E-mail : suresh@rri.res.in. Tel: +91-80-28382924. Fax: +91-80-23610492. 


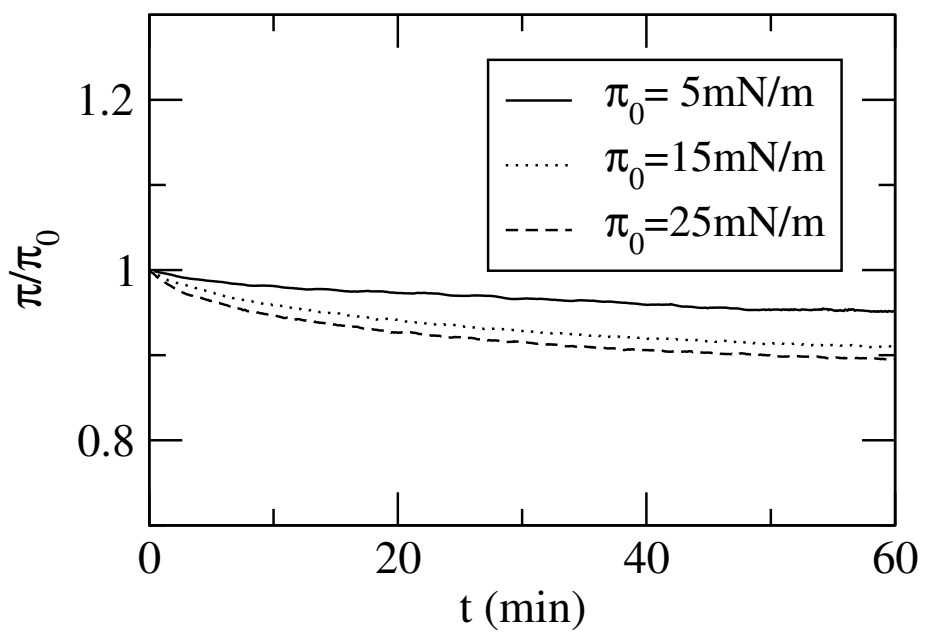

Figure S1: Surface pressure $(\pi)$ - time $(\mathrm{t})$ relaxation isotherms (normalized to $\pi / \pi_{0}$ ) of PyTp-DNA complex monolayer at constant area for various surface pressures $\left(\pi_{0}\right)$.
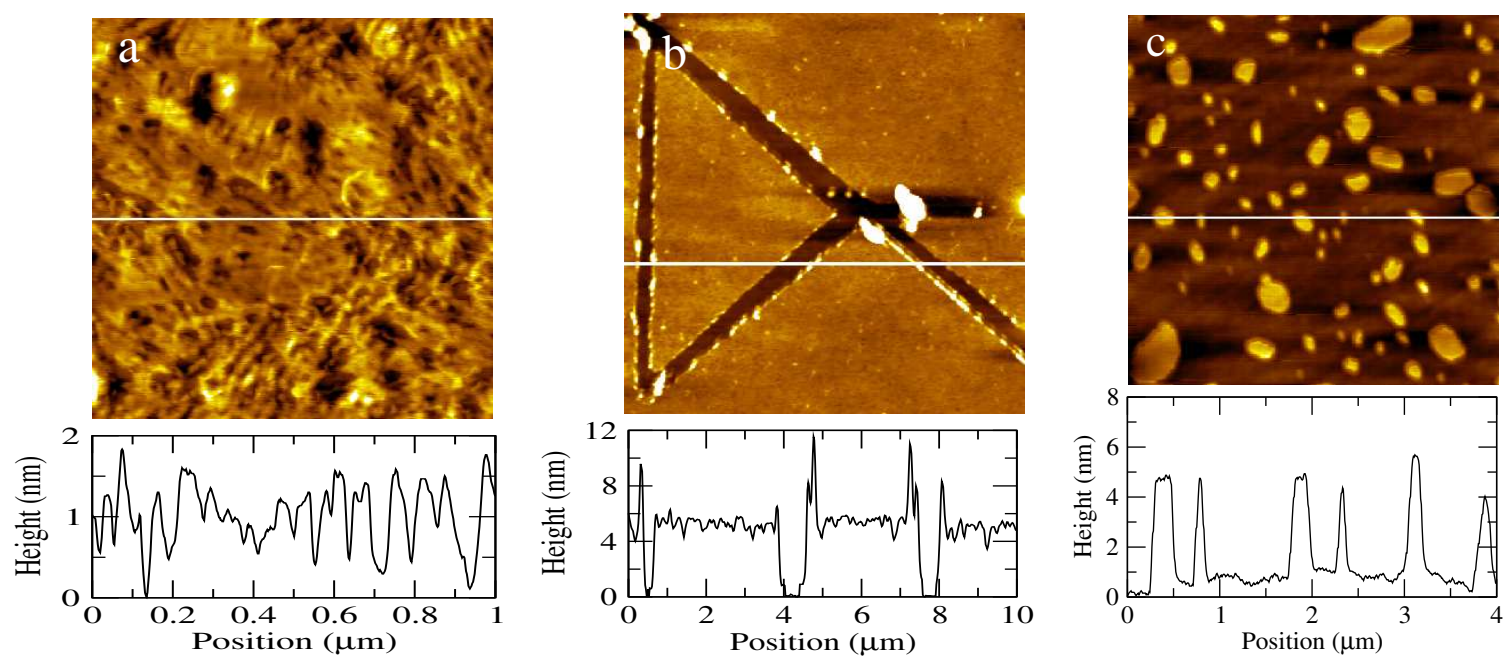

Figure S2: AFM topography images for 3 layers of PyTp-DNA complex film transfered at 35 $\mathrm{mN} / \mathrm{m}$ onto hydrophilic silicon substrates. (a) Morphology of the film surface showing roughness. (b) Scratched film to measure the thickness. The film was compact with a roughness of about 1.2 $\mathrm{nm}$ and thickness of about $7.5 \mathrm{~nm}$. The film was scratched in three different directions for better reproducibility. (c) 3 layers of pure PyTp film transfered at $35 \mathrm{mN} / \mathrm{m}$ onto hydrophilic silicon substrate showing desorption. The respective height profiles corresponding to the white lines on the images are shown below. 

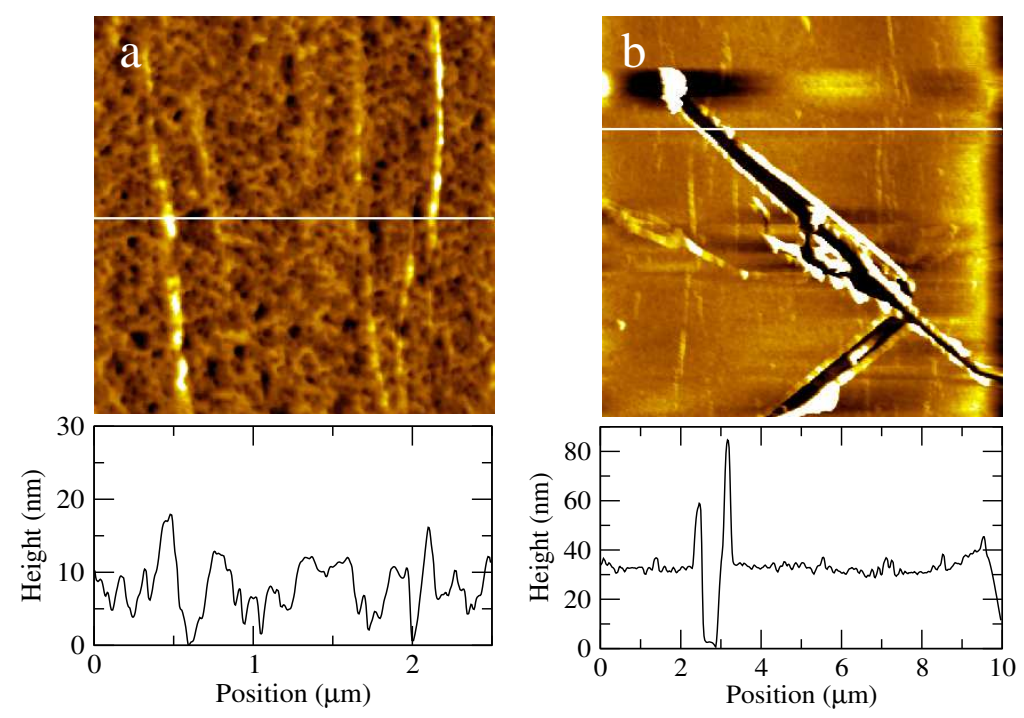

Figure S3: AFM topography images of 12 layers of PyTp-DNA complex film transfered at 35 $\mathrm{mN} / \mathrm{m}$ onto hydrophobic silicon substrates. (a) Morphology of the film showing DNA bundles aligned in the film deposition direction. (b) Scratched film to measure the thickness which was about $32 \mathrm{~nm}$. The respective height profiles corresponding to the white lines on the images are shown below.
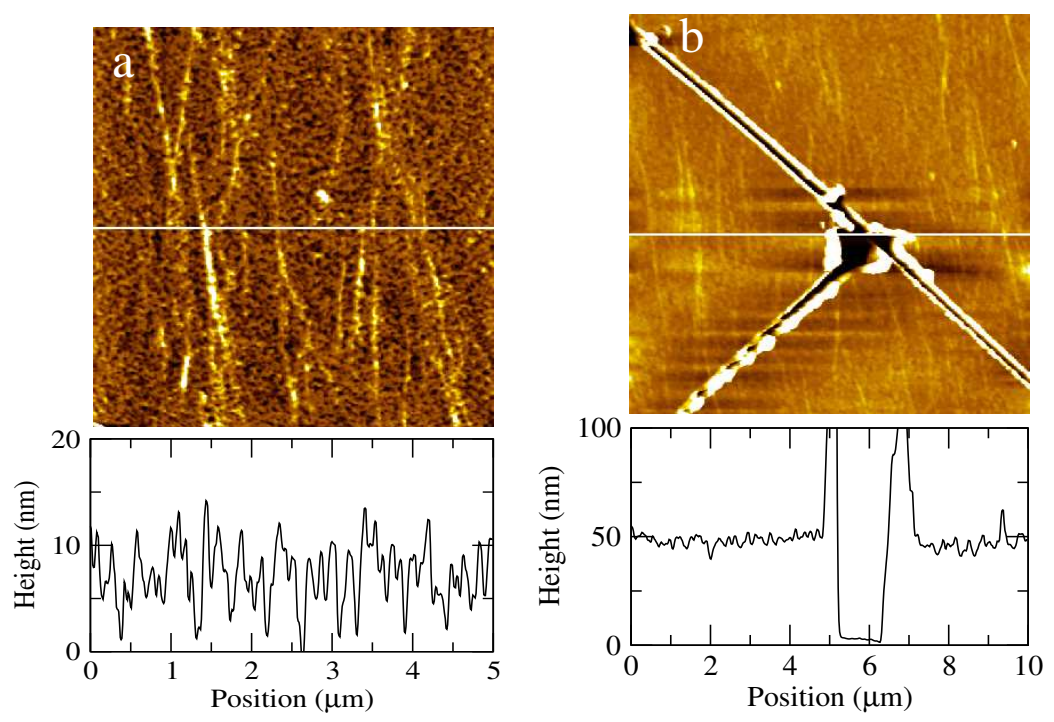

Figure S4: AFM topography images for 20 layers of PyTp-DNA complex film transfered at 35 $\mathrm{mN} / \mathrm{m}$ onto hydrophobic silicon substrates. (a) Morphology of the film surface showing roughness. (b) Scratched film to measure the thickness. The respective height profiles corresponding to the white lines on the images are shown below. 
$\mathbf{a}$

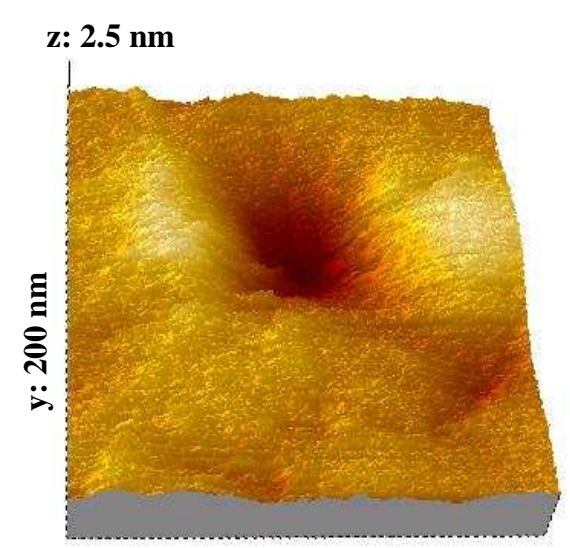

$\mathrm{x}: 200 \mathrm{~nm}$ b

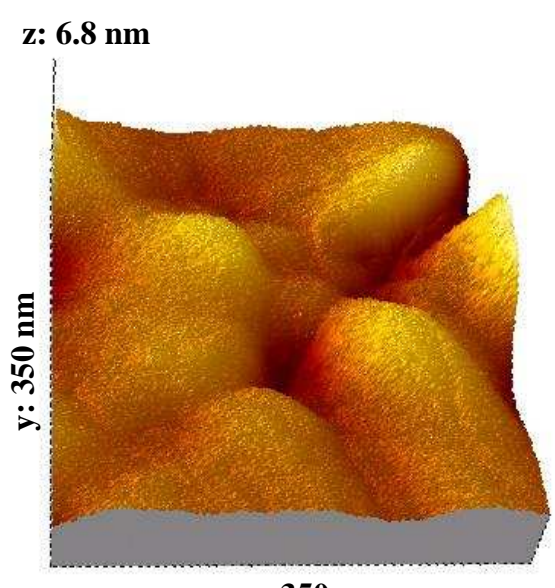

$\mathrm{x}: 350 \mathrm{~nm}$

Figure S5: Typical AFM 3D images showing the topography of the indents formed on (a) 2 layers of pure PyTp film surface after indenting with a load of $9 \mathrm{nN}$ and, (b) 2 layers of PyTp- DNA complex film surface after indenting with a load of $18 \mathrm{nN}$.

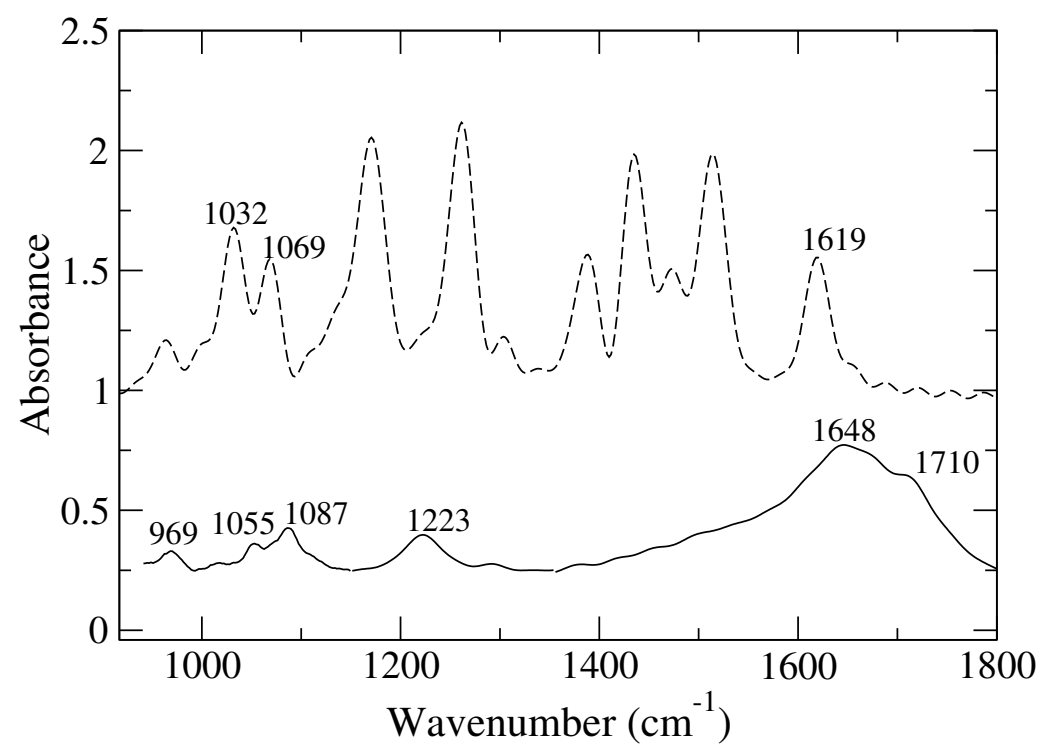

Figure S6: FTIR absorption spectrum of monolayer of pure PyTp LB film on hydrophilic silicon substrate (dashed line). The solid line shows the absorption spectrum of pure DNA at a concentration of $2 \mathrm{mg} / \mathrm{ml}$ in water applied on silver chloride plate. 